\title{
Movilidad urbana en la Patagonia norte argentina: una aproximación a la ciudad turística de San Carlos de Bariloche.
}

Urban mobility in northern Argentine Patagonia: an approach to the tourist city of San Carlos de Bariloche.

\author{
Víctor Damián Medina ${ }^{\mathrm{a}}$ \\ Historial del artículo \\ a CONICET-CIETES / Universidad de Río Negro, Argentina. Correo electrónico: damianviktor@yahoo.com.ar \\ Recibido: \\ 26 de junio de 2019. \\ Aceptado: \\ 22 de julio de 2019.
}

\section{Palabras clave \\ Ciudades turísticas, desigualdad espacial, movilidades urbanas, San Carlos de Bariloche}

\begin{abstract}
Resumen
El giro a la movilidad ha supuesto el reconocimiento de distintas situaciones de desigualdad espacial relativas a los desplazamientos diarios en las ciudades. El presente artículo propone abordar este tipo de asimetrías en San Carlos de Bariloche, una ciudad turística de montaña donde las bajas temperaturas y el relieve accidentado de su suelo caracterizan su entorno ambiental. Se postula que la tenencia de transporte privado interviene decisivamente en las capacidades de movilidad de sus habitantes, amén de otras alternativas de locomoción y de la mayor o menor distancia a núcleos de aprovisionamiento. Para verificar esto se analizan las experiencias de viaje de los pobladores de dos barrios diferencialmente distantes del casco céntrico que además representan distintos perfiles socioeconómicos. La metodología cualitativa adoptada se basa en entrevistas en profundidad realizadas a diez habitantes de los barrios San Francisco y Casa de Piedra. A partir de la indagación de sus trayectos cotidianos, y de los de los miembros de su hogar, se concluye que la capacidad de moverse es menor entre los habitantes de los San Francisco, lo cual no solo tiende a acotar sus desplazamientos y potenciales viajes, sino también la experimentación y apropiación de los distintos espacios de la ciudad.
\end{abstract}

\section{Abstract}

The mobility turn has supposed the recognition of different situations from space inequality related to daily displacements in cities. The present article proposes to approach this type of asymmetry in San Carlos de Bariloche, a mountain tourist city where the low temperatures and the rugged relief of its soil characterize its environment. It is postulated that the possession of private transport takes part decisively in the mobility capacities of its inhabitants, in addition to other alternatives of locomotion and the greater or lesser distance to central business district (CBD). To verify this, the travel experiences of the residents of two neighborhoods differentially distant from the CBD that also represent different socioeconomic profiles are analyzed. The qualitative methodology adopted is based on in-depth interviews made to ten inhabitants of the San Francisco and Casa de Piedra neighborhoods. From the investigation of their daily journeys, and those of the members of their household, it is concluded that the ability to move is lower among the inhabitants of San Francisco, which not only tends to limit their travel and potential trips, but also the experimentation and appropriation of the different spaces of the city. 


\section{Introducción}

El llamado giro a la movilidad supone en principio un conjunto de estudios anglosajones que colocan en escena y remarcan la importancia de las prácticas de viaje como formas de habitar la ciudad (Cresswel, 2011; Merriman, 2014; Scheller \& Hurry, 2000;).

La mecanización que lograron los medios de transporte por medio de los avances técnicos se tradujeron no sólo en cambios en los modos de viajar, en la velocidad de los traslados a sitios otrora lejanos, sino que también dejaron su sello en la socialización de las personas, esto es, en la formación de subjetividades de género, de familia, de lazos sociales (Sheller \& Urry, 2006). En tal sentido, se destacan el rol trascendental que tuvo el acceso generalizado al ferrocarril para modificar las formas de experimentación del espacio y el tiempo (Schivelbusch, 1986), al igual que la invención del transporte motorizado - particularmente el automóvil (Sheller \& Urry, 2000; Wolfe, 2010) —, pero también las tecnologías de la comunicación, en tanto y en cuanto permitieron trastocar las formas de percibir las distancias (Schivelbusch, 1986; Sheller \& Urry, 2006).

En América Latina también hay investigaciones que recuperan las relaciones sociales construidas en el marco de determinadas prácticas de movilidad: muchas de ellas resaltan las experiencias de viaje de ciertos transportes públicos como buses, tranvías y trenes (Muñoz, 2013; Errázuriz, 2014; Pérez, 2014; Zunino Singh, 2014). Así, por ejemplo, cobran protagonismo las desigualdades urbanas que reproducen algunos de ellos, como el ferrocarril en el área metropolitana de Buenos Aires y el servicio deficitario que ofrece para muchos grupos sociales de bajos recursos que cautivamente hacen uso de él (Pérez, 2014); o también, para el caso de México, el diseño y la inversión en infraestructura vial que tiende a favorecer la circulación del transporte privado por sobre otras alternativas de movilidad (Pérez Negrete, 2015).

A su vez, otros estudios señalan los vínculos que existen entre algunas características espaciales de las ciudades ocupación de áreas periféricas, redistribución de población y actividades en centros secundarios- $-y$ las movilidades urbanas como elementos asociados a la polarización y segregación espacial (Jirón, Lange \& Bertrand, 2010). En estos casos también asoma como problema la mayor y menor accesibilidad que experimentan determinados grupos sociales, y como tal fenómeno puede derivar en diversas formas de exclusión social (Jirón \& Mansilla, 2013). También se apunta el predominio del transporte privado — en la figura del automóvil—y la realización de obras de infraestructura vial como catalizadores de la expansión periurbana de las ciudades, y algunas de las asimetrías espaciales que conlleva (Galimberti, 2018).

Por otro lado, en un plano material, pero también más simbólico de apropiación del territorio, algunos autores vinculan ciertas prácticas de movilidad a diversos perfiles socioeconómicos de usuarios de medios de transporte (Blanco, Bosoer \& Apaolaza, 2014).

El hecho de poder dirigirse a distintos lugres de la ciudad gracias al avance técnico de los medios de locomoción motorizados, también sitúa a la movilidad como relación y como práctica social que "pone en juego las necesidades de los sujetos para desarrollar sus actividades de reproducción de la vida social, en un cierto contexto territorial y temporal" (Blanco et al., 2014, p. 3). Siguiendo esta idea cabe entonces la distinción entre transporte y movilidad introducida por Gutiérrez (2012): la movilidad es una práctica social, o performance, que emplea al transporte como medio o instrumento para poder desplazarse en el espacio físico pero que no empieza ni acaba en él. Lo que define a la movilidad son las prácticas y las maneras de trasladarse sin que las mismas supongan necesariamente la realización del viaje, y menos aún por intermedio de transportes motorizados (Avellaneda \& Lazo, 2011). De esta manera, las necesidades de viaje comportan un contexto subjetivo de sentido que no se vinculan al lugar per se, al mero hecho de acceder a él, sino al significado que tiene para la vida cotidiana de los agentes las actividades que realizan en cada lugar al que acceden (Gutiérrez, 2012, p. 68).

Conviene considerar entonces las diferentes capacidades de movilidad, o motilidad, que tienen las personas para desplazarse por la ciudad, incluyendo también la capacidad de poder evitar estos desplazamientos (Kaufmann, Bergman \& Joye, 2004; Ohnmacht, Maksim \& Bergman, 2009). Por este motivo, la motilidad no solo contempla los avances técnicos en materia de transporte, en tanto facilitadores del movimiento, sino también a las tecnologías de la comunicación, en tanto y en cuanto permiten economizar y/o evitar los traslados físicos (Flamm \& Kaufmann, 2006, p. 169). En este orden, de acuerdo a Kaufmann, et al. (2004), la motilidad se compone de tres dimensiones: el acceso, la competencia y la apropiación. El acceso hace referencia a los límites a la movilidad que implican las condiciones materiales de existencia y el contexto social y económico, el entorno del lugar, en el que desarrollan su vida cotidiana las personas. Estos límites pueden estar vinculados a las condiciones de infraestructura y a los medios de transporte y comunicaciones disponibles, así como los costos económicos que suponen su uso. La 
competencia es un atributo relacionado a las habilidades personales, entre las que se incluyen capacidades derivadas de las condiciones físicas y/o etarias, pero también otras adquiridas, como las inherentes al reconocimiento de los lugares, la organización de los traslados, y saber conducir transportes motorizados, entre otras. Por último, la apropiación refiere a cómo los agentes de movilidad experimentan, interpretan y comprenden los espacios a los que acceden y las habilidades, $u$ opciones adecuadas, que son necesarias para ello. Estas tres dimensiones permiten discernir las condiciones de movilidad de los agentes, el modo en que resuelven, según su contexto, muchas de las necesidades de traslado - fundamentalmente, con fines laborales, educativos y/o recreativos - y los vínculos diferenciales y desiguales que mantienen con los distintos espacios de la ciudad.

Teniendo en cuenta estas dimensiones de la motilidad, y las desiguales capacidades de movilidad que pueden vertebrarse a partir de ellas, es que cobra interés específico el estudio de las movilidades urbanas en una ciudad como San Carlos de Bariloche. Este centro turístico de la Patagonia norte argentina, localizado en la provincia de Río Negro, históricamente ha soportado procesos de urbanización difusos, de baja densidad y de estrecho vínculo con el entorno natural, rasgos todos que, a su vez, también han supuesto la cristalización de distintas desigualdades espaciales (Abaleron, 1992; Kropff, 2002; Matossian, 2011; Medina, 2017; Méndez, 2010) (Figura 1).
El extenso territorio de esta localidad andina, de aproximadamente 45 kilómetros de largo por 9 de ancho, y las más de 27.000 hectáreas que conforman el ejido, superior incluso al de la capital de Argentina - Buenos Aires - , trazan una compleja y heterogénea realidad social en la que conviven tanto los sectores de mayor poder adquisitivo, que generalmente ocupan la franja costera de mayor relieve paisajístico, como los sectores populares y de ingresos medios que residen en los lugares de menor atractivo turístico y ambiental. Así, por ejemplo, de manera muy esquemática, suele presentarse en buena parte de la bibliografía citada una suerte de dualidad social y económica entre el núcleo de la actividad turística, localizada predominantemente en el centro y "los kilómetros"(en el hablar cotidiano local, se denomina así a toda el área ubicada al Oeste del casco céntrico), y los barrios populares “del alto", donde dramáticamente se concentran y localizan los mayores índices de pobreza, se registra un mayor caudal de nieve y, en general, las temperaturas son más bajas. Sin embargo, al margen de estas fronteras urbanas y las polarizaciones que se ciernen sobre el territorio - que notoriamente aparecen en el imaginario colectivo y en no pocos libros y artículos académicos - , no hay abordajes que prioricen, o al menos remitan, a las movilidades urbanas como un factor interviniente en la conformación de estas desigualdades y, particularmente, el rol que pueden tener los medios de locomoción modernos en la disminución de los tiempos de traslado (Schivelbusch, 1986; Sheller \& Urry, 2006). Si bien existen estudios de consultoras

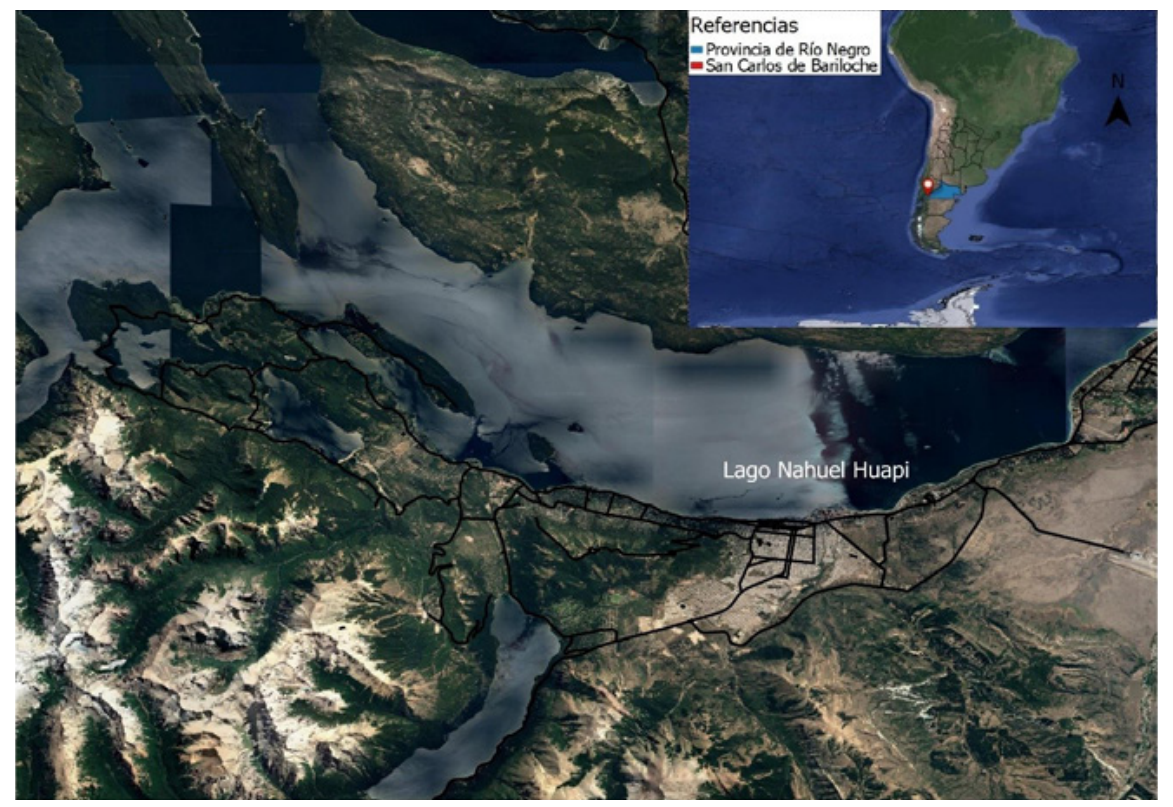

Figura 1. Localización de San Carlos de Bariloche. Fuente: Elaboración propia (2019) en base a Google Earth. 
privadas que han analizado las condiciones de movilidad en la ciudad, estas suelen enfocarse en aspectos más bien físicos, de infraestructura - relevando algunas de sus carencias-, y el funcionamiento del transporte público, como ejes a optimizar en pos de mejorar el tránsito urbano (IRV LOGIT, 2014; Mohana, 2004; Solivérez, 2014). En cambio, brilla por su ausencia la perspectiva de los pasajeros, de aquellos que habitualmente deben moverse y recorrer largas distancias para llevar a cabo diversas actividades, laborales y educativas, predominantemente, pero también de ocio y esparcimiento.

Así, tomando en cuenta las bajas temperaturas que predominan durante buena parte del año y el estado disruptivo y en pendiente del suelo barilochense, debe repararse en el papel que cumplen medios de transporte como el bus y el automóvil en los desplazamientos diarios. En tal sentido, es elocuente la gran afluencia de automóviles (se estima que existe 1 automóvil cada 2 personas. A nivel nacional esta proporción era de 1 vehículo cada 3,8 habitantes en 2017, http://www.afac. org.ar/paginas/noticia.php?id=2170) y los habituales problemas de tránsito que ocurren en la ciudad (Diario Río Negro (12-1-17) y portal de noticias ANB (27-1213)), en tanto indicadores de las distintas necesidades que se satisfacen a partir de ellos. A su vez, las tendencias extensivas de crecimiento de la ciudad y, particularmente, la suburbanización y separación de los distintos barrios sugieren en sí mismas la importancia que adquirieron los vehículos a motor en la reducción temporal de las distancias, suscitando interrogantes en torno a cómo los habitantes afrontan cotidianamente sus necesidades de traslado y de qué modo las diferentes capacidades de movilidad pueden llegar a resolverlas.

El objetivo del artículo es entonces analizar desde un enfoque cualitativo cómo estas capacidades de movilidad operan, en una ciudad con severos condicionamientos ambientales, físicos y climatológicos, en el desplazamiento cotidiano de la población. Y discernir cómo, en efecto, las movilidades urbanas pueden llegar a constituir una expresión más de las asimetrías locales. Para responder a estas cuestiones se tomarán en cuenta las experiencias de viaje y los medios de traslado que suelen utilizar con mayor frecuencia los habitantes de dos barrios alejados diferencialmente del casco céntrico de San Carlos de Bariloche: un barrio de medianos-altos ingresos localizado en el kilómetro 14, al Oeste del casco céntrico, llamado "Casa de Piedra"; y un barrio más cercano, localizado al Este, a aproximadamente 2 kilómetros del centro, que históricamente fue habitado por grupos sociales de medianos y bajos ingresos, el "San Francisco". En este orden, lo que aquí se postula es que los habitantes de San Francisco tienen una menor capacidad de movilidad que los de Casa de Piedra, lo cual comporta no solamente mayores dificultades de traslado, a pesar de habitar en las adyacencias del casco céntrico, lo que a priori supondría estar menos sujetos a las condiciones climáticas y topográficas de la ciudad por su cercanía a lugares de concentración y dotación de bienes y servicios - entre ellos, el transporte público-, sino también restricciones relativas a los viajes posibles y la apropiación de los distintos espacios urbanos.

El artículo se estructura de la siguiente manera. En un primer apartado se detalla el enfoque metodológico utilizado para corroborar la hipótesis. Luego se avanza en los resultados. En principio se describen las condiciones generales de infraestructura y acceso vial de la ciudad, sobre todo en lo relativo a la pavimentación de sus calles y principales conectores. Seguidamente - conformando el núcleo central del análisis - son introducidos los casos de estudio elegidos y los relatos de los entrevistados. Posteriormente, se discuten y analizan los resultados obtenidos a la luz del marco teórico propuesto. Finalmente, en el apartado dedicado a las conclusiones, se retoman la hipótesis y los objetivos del artículo, destacando lo que ha sido verificado y las posibles líneas de investigación futuras.

\section{Método y materiales}

La investigación se basa en un enfoque metodológico cualitativo. Si bien se apoya fundamentalmente en la entrevista en profundidad, también se emplean, subsidiariamente, fuentes secundarias relativas a las características de la trama vial de San Carlos de Bariloche y sus condiciones de infraestructura. A este respecto, se recurre a dos planes de ordenamiento territorial formulados en distintos períodos, los cuales permiten identificar los rasgos más salientes de dicha trama y vincularla al crecimiento urbano que caracteriza a la ciudad. Este acercamiento ayuda a su vez, a comprender la participación de la trama vial en las condiciones que permitieron la creación de muchos de los barrios y, particularmente, de uno de los barrios objeto de estudio. En segunda instancia, se hace uso de entrevistas en profundidad realizadas a cinco habitantes de cada barrio a fin de poder dilucidar, a partir de una descripción densa (Geertz, 1987) de sus experiencias de viaje y la cotidianeidad de sus trayectos diarios, el modo en que sus capacidades de movilidad (Kaufmann et al., 2004) y la de los miembros de su hogar se articulan con las características de la ciudad mencionadas. A través de esta técnica de análisis se pretende indagar en las valoraciones subjetivas de los agentes, los deseos y motivaciones que conllevan la necesidad de desplazamiento, así como las 
capacidades de los mismos para hacerlos efectivos (o no) y en qué medida y bajo qué circunstancias. Haciendo uso de la técnica "bola de nieve", con información aportada por informantes clave y otros contactos (incluidos los mismos vecinos), se procuró entrevistar a cinco mujeres y cinco varones, mayores de 18 años, que representaran distintas situaciones de inserción como miembros (o no) de la población económicamente activa (como suele acostumbrarse en estudios de este tipo, se apeló a nombres ficticios para preservar las identidades de los entrevistados). Las preguntas que se formularon apuntaron a discernir los desplazamientos más frecuentes (laborales, educativos, de salud y/o de ocio), qué miembros del hogar los realizan, cuales son los medios de transporte que suelen utilizar, los problemas de tránsito y circulación que identifican en la ciudad — sobre todo aquellos que más los afectan-, así como la distancia y el tiempo que emplean para trasladarse. En este orden, se tienen en cuenta también las condiciones vinculadas a los viajes no realizados, tanto los potenciales que son concebidos como aquellos que no forman parte, en general, de la planificación de sus vidas cotidianas.

\section{Resultados}

San Carlos de Bariloche: características generales de su trama vial

La fundación de San Carlos de Bariloche se formalizó, mediante un decreto del poder ejecutivo nacional, con la creación de la Colonia agro-pastoril Nahuel Huapi y la reserva de tierras del casco urbano del - por aquel entonces - poblado San Carlos en 1902. A pesar del relieve irregular y de sus pronunciadas pendientes, se implantó una traza divisional en damero -propio del llano pampeano y de muchas ciudades fundadas en esa época- que inicialmente abarcó las primeras cinco manzanas y la calle
Mitre, a posteriori principal arteria turística y comercial de la ciudad. Este primer trazado terminaría completándose entre 1905 y 1911, definiendo una grilla de 87 manzanas cuadradas que constituirían parte del casco céntrico. Luego de estos primeros años de expansión del centro, no hubo demasiados cambios en cuanto a infraestructura y dotación de servicios. Si bien entre 1934 y 1944 se habían asfaltado las principales calles, que corren en paralelo al Lago, como la Avenida Costanera, Mitre, Moreno y Elflein (Plan de Ordenamiento Territorial, 2010), a mediados de la década de 1970 la cobertura asfáltica hacia el Sur cubría solo hasta la calle Tiscornia, esto es, no más del $20 \%$ del total (Suárez, 1977). Conviene mencionar esto ya que en la actualidad son muchas las calles que todavía no han sido asfaltadas, incluso muchas situadas en el casco céntrico o en sus inmediaciones, correspondiéndose también con la falta de veredas y otras carencias de infraestructura urbana propias de la ciudad. Hacia 2010 solo el $24 \%$ de los conectores viales estaba pavimentado, incluyendo la Avenida de la circunvalación inaugurada en 2006, y la mayoría correspondía a rutas provinciales y nacionales (tabla 1).

Complementariamente, para entender la difusión y extensión territorial de índole suburbana que acabó teniendo, debe mencionarse la existencia temprana de los conectores viales que vinculan a San Carlos de Bariloche con el exterior, y que constituyen los ejes troncales que atraviesan su ejido, puesto que en conjunto permiten la interrelación con otros caminos y accesos. Deben señalarse entonces la Avenida Bustillo (ex ruta nacional 237), el camino por el faldeo del cerro Otto a través de la ruta provincial 82 (ex ruta nacional 253), la actual Avenida Juan Herman (ex ruta nacional 258) y la ruta nacional 40 que, dirigiéndose hacia a El Bolsón, atraviesa la ciudad por la Avenida Circunvalación.

Tabla 1

Normalización del riesgo volcánico.

\begin{tabular}{|c|c|c|c|c|c|c|c|c|}
\hline RED VIAL & \multicolumn{2}{|c|}{ Centro Urbano Norte } & \multicolumn{2}{|c|}{ Centro Urbano Sur } & \multicolumn{2}{|c|}{$\mathrm{Km} 1 \mathrm{al} \mathrm{km} 8$} & \multicolumn{2}{|c|}{ Resto del ejido } \\
\hline $\begin{array}{l}\text { Calles } \\
\text { Pavimentadas }\end{array}$ & $57 \mathrm{~km}$ & $48 \%$ & $8 \mathrm{~km}$ & $15 \%$ & $4 \mathrm{~km}$ & $4 \%$ & $3 \mathrm{~km}$ & $1 \%$ \\
\hline $\begin{array}{l}\text { Ruta } \\
\text { Pavimentada }\end{array}$ & $3 \mathrm{~km}$ & $3 \%$ & $1 \mathrm{~km}$ & $2 \%$ & $13 \mathrm{~km}$ & $13 \%$ & $81 \mathrm{~km}$ & $18 \%$ \\
\hline Calle Ripio & $58 \mathrm{~km}$ & $49 \%$ & $44 \mathrm{~km}$ & $83 \%$ & $80 \mathrm{~km}$ & $82 \%$ & $285 \mathrm{~km}$ & $64 \%$ \\
\hline Ruta Ripio & $0 \mathrm{~km}$ & $0 \%$ & $0 \mathrm{~km}$ & $0 \%$ & $0 \mathrm{~km}$ & $0 \%$ & $74 \mathrm{~km}$ & $17 \%$ \\
\hline Total & $118 \mathrm{~km}$ & $100 \%$ & $53 \mathrm{~km}$ & $100 \%$ & $97 \mathrm{~km}$ & $100 \%$ & $443 \mathrm{~km}$ & $100 \%$ \\
\hline
\end{tabular}

Fuente: Municipio de San Carlos de Bariloche. 


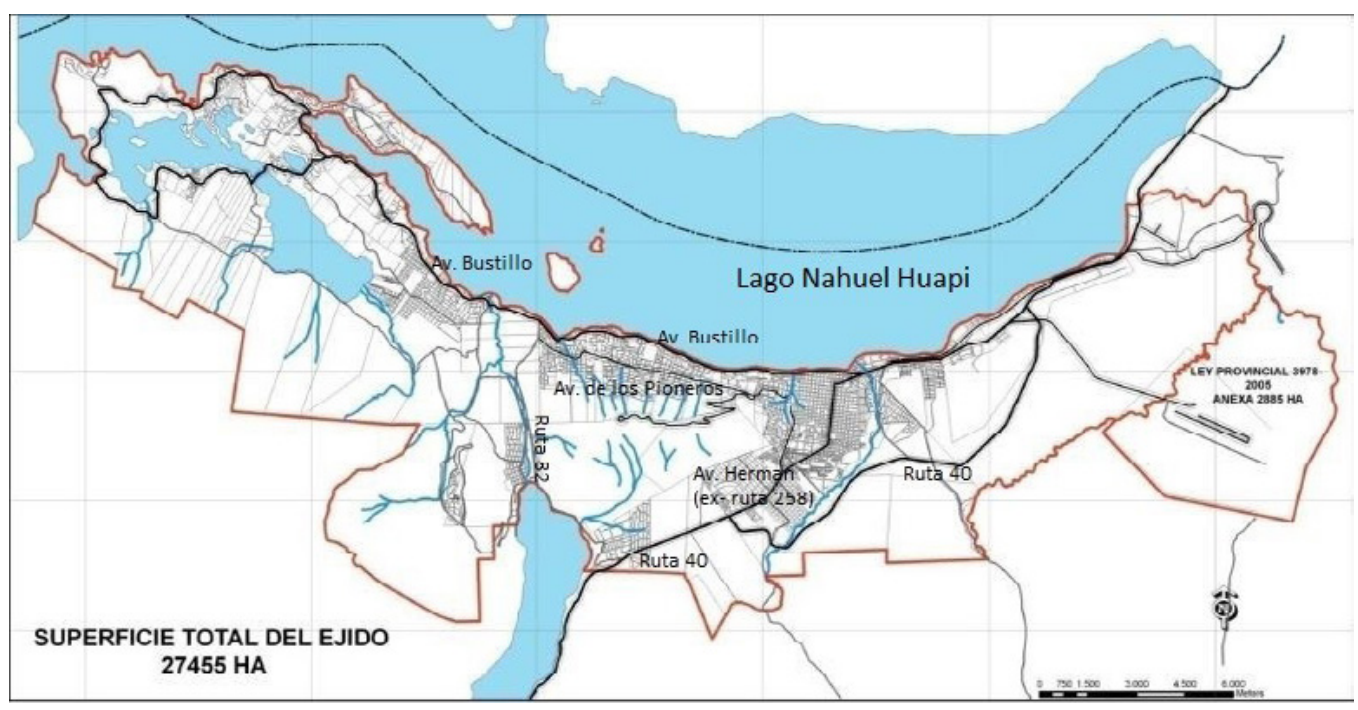

Figura 2. Principales conectores viales, 2010. Fuente: Elaboración propia (2019) en base a mapa del Municipio de San Carlos de Bariloche.

De estos cuatro conectores, dos de los cuales comportan vías de entrada y salida a la ciudad, la Avenida Bustillo trazada entre los años 1937 y 1940 (cuando se inauguró su pavimentación) — es la que representa arquetípicamente el sentido Centro-Oeste que históricamente tuvo el crecimiento urbano local (en una longitud cercana a los 30 kilómetros). Junto a la Avenida de Los Pioneros, que corre en forma paralela un poco más al Sur, constituyen las dos arterias principales que atraviesan longitudinalmente a la ciudad, y que permiten a su vez alcanzar los sitios turísticos localizados al Oeste (Figura 2).

\section{Movilidades en los barrios San Francisco y Casa de Piedra}

Los barrios San Francisco forman parte de los pocos barrios populares de Bariloche que no siguieron la tendencia de crecimiento típica hacia la periferia Sur. Se sitúan al Este y Sudeste del casco céntrico, sobre la avenida de ingreso y salida de la ciudad. El barrio más antiguo es el San Francisco 1 (Figura 3 y 4), cuya junta vecinal se creó en los albores de la década de 1980, aunque los primeros asentamientos datan de la década anterior (Guevara y Medina, 2017). Los barrios San Francisco II-III y IV surgieron más tardíamente, al calor de las demandas habitacionales, continuando la expansión del San Francisco I en dirección Sur y Sudeste. Si bien comparten algunas de las carencias generalizables a otros barrios populares, cuentan con la cobertura de la mayoría de los servicios, sobre todo en el caso del San Francisco I.

Por otro lado, el barrio Casa de Piedra se encuentra localizado entre los kilómetros 13 y 15 de la Avenida
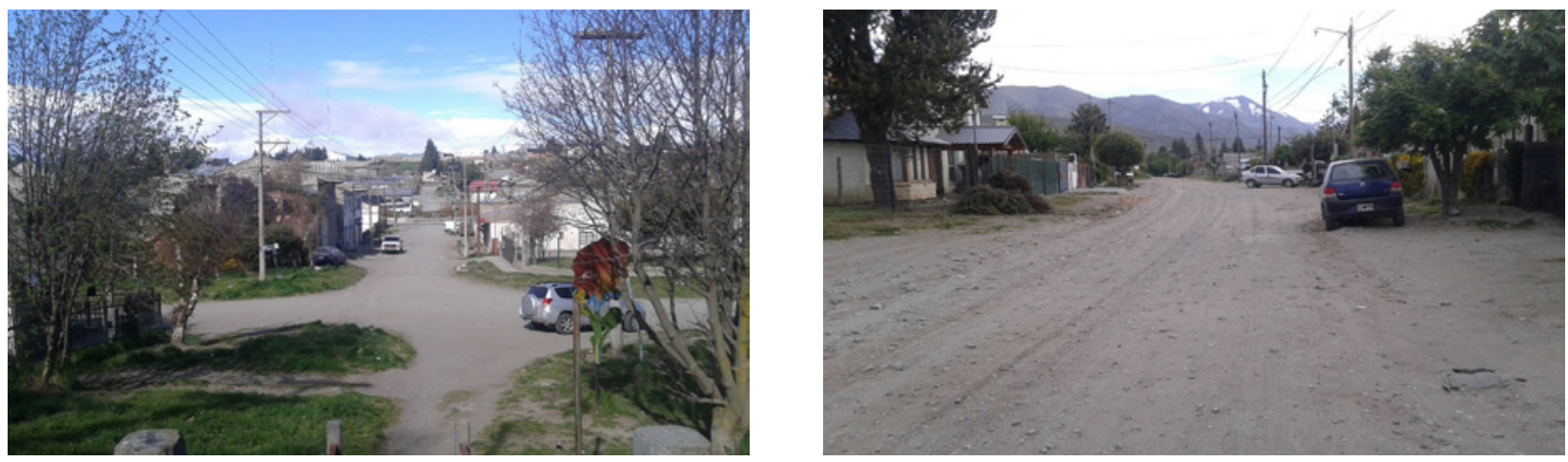

Figura 3. Barrio San Francisco I, 2018. Fuente: Fotografía del autor (2018)

Figura 4. San Francisco III, 2018. Fuente: Fotografía del autor (2018) 
Bustillo. Forma parte, junto a barrios como Pájaro azul y Nahuel Malal, de los conjuntos residenciales de los sectores medios vinculados al sector de ciencia y técnica, particularmente a la Comisión nacional de Energía Atómica, lugar de trabajo de muchos de sus habitantes. Este es uno de los barrios del Oeste que comenzó a crecer de manera significativa durante el transcurso de los años 2000. A diferencia de los San Francisco, sobre todo del San Francisco I, de fisonomía más "urbana" y de usos del suelo más diversificados, Casa de Piedra es un barrio marcadamente residencial, de terrenos y casas amplias, y de estrecho vínculo con el entorno natural de la zona, donde la mayoría de sus calles son de ripio. Sus lotes, de grandes dimensiones y abundante vegetación, escenifican buena parte del paisaje típico de la región andina que, a tono con otros barrios residenciales y de viviendas bajas, permiten reconocer la convivencia de urbanidad y naturaleza característica de la ciudad (Medina, 2017) (Figuras 5, 6 y 7).
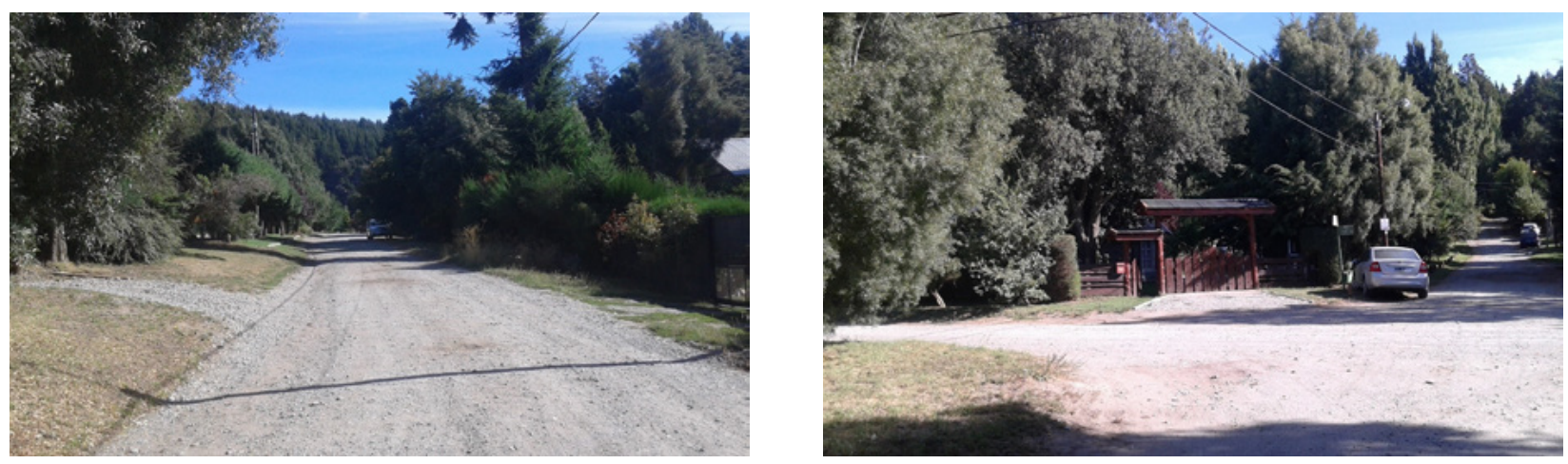

Figura 5. Barrio Casa de piedra, 2018. Fuente: Fotografía del autor (2018)

Figura 6. Barrio Casa de piedra, 2018. Fuente: Fotografía del autor (2018)

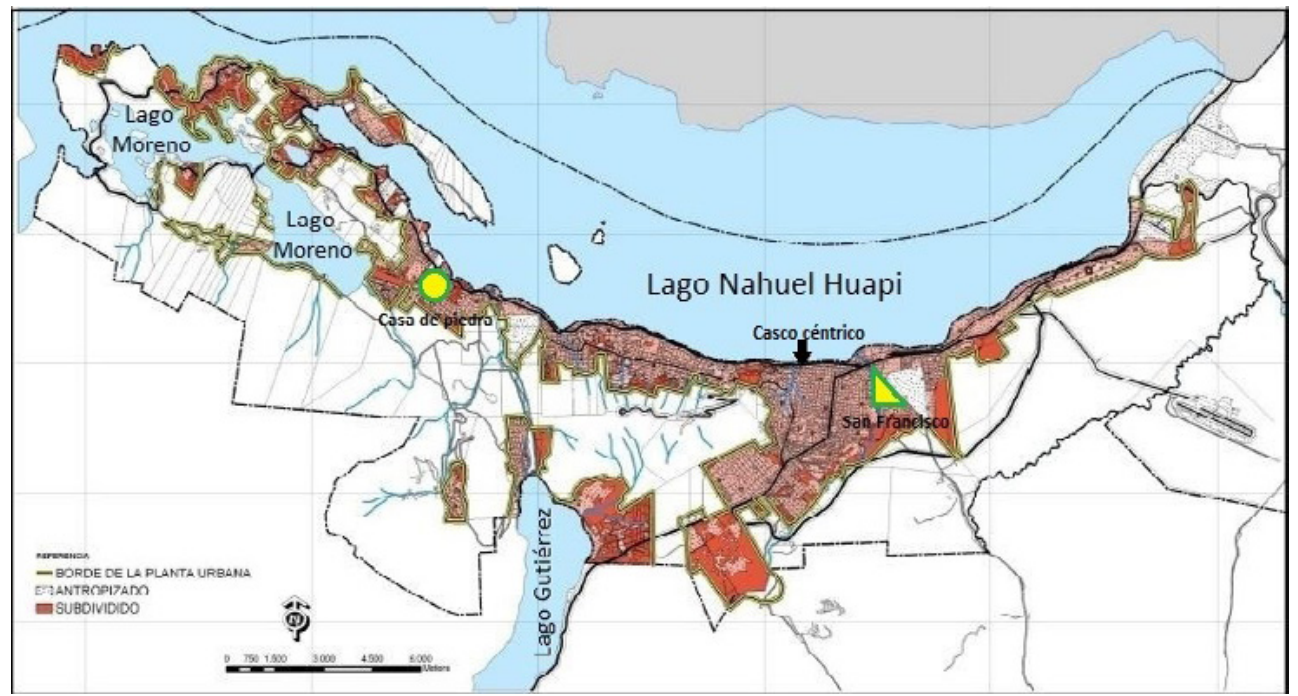

Figura 7. Localización de los barrios San Francisco y Casa de piedra. Fuente: Elaboración propia (2019) en base a mapa de la Secretaría de Desarrollo Urbano. 
Hacia el San Francisco. La Avenida Esandi es un conector vial de acceso a la circunvalación de Bariloche, pero también es un vaso comunicante con los barrios que la bordean, entre ellos los San Francisco, y particularmente donde vive José, el San Francisco IV. José trabaja en la delegación municipal de El Cóndor haciendo tareas de barrido y reparación de pavimento, por lo que sus trayectos cotidianos se estructuran mayoritariamente en función de su trabajo. Aunque por la cercanía a su vivienda podría optar por caminar, siempre se traslada en automóvil: tarda apenas 5 minutos en llegar, lapso que puede extenderse a 15 durante el invierno, por precaución ante el hielo acumulado en la acera. Además de él, que cuenta con 58 años, el hogar lo integran su esposa, de 61, y su hijo menor, de 25 (el resto de sus hijos ya abandonó el nicho parental). Los dos varones del hogar disponen de automóvil propio y ambos estructuran sus actividades, principalmente las laborales, en función de los traslados que permiten estos dos medios de locomoción: el hijo, que también trabaja en el Municipio, mantiene su rol de conductor, ya que es chofer. Aparte de estos trabajos fijos, suelen realizar, también, changas ocasionales. La esposa de José, en tanto, es jubilada y ama de casa: no dispone de auto propio, y cuando ocasionalmente necesita trasladarse para hacer sus trámites, pago de servicios, etc., usa el colectivo (bus). Al margen de lo laboral, la utilidad del automóvil se recrea al momento de proveerse de artículos del hogar en supermercados mayoristas. José no imagina otro medio de traslado que no sea a partir del automóvil: "caminar sería lo más lógico, lo más lindo. Uno, porque uno ya está excedido de peso, por cosas así sería bueno caminar, pero por comodidad elige el auto". Por otro lado, asocia la opción de ir "a pie" a la situación económica del país:

El tema que es la parte de gobierno está afectando todo. Creo que de un tiempo más vamos a estar caminando todos; no sé si vamos a alcanzar a tener bicicletas. Fijáte que tiempo a tiempo, estas cosas se van notando más: comés o salís en tu auto, porque hoy por hoy nuestros sueldos están bajos. (José, Hacia el San Francisco, 2018)

Asimismo, si bien destaca que en general es un caos manejar en Bariloche durante las horas pico, la ubicación de su trabajo lo beneficia, a contrapelo de muchos de sus vecinos que deben dirigirse al centro. El colectivo, y las dos líneas que transitan el barrio, la 60 y la 61 , no son una opción por su baja frecuencia. Tampoco para su hijo que, de acuerdo al entrevistado, lo une una relación más estrecha con el automóvil: "ese no se baja nunca del auto; si no anda en auto, anda en camioneta, no camina nunca; nació en un auto el hijo de puta". Ni siquiera el clima y las complicaciones que suele acarrear la nieve comportan un obstáculo si José y su primogénito disponen de autos: "siempre tuvimos suerte; solemos ir bien engomados, con cadenas; como corresponde, ¿no?”. Si bien señala la proverbial deficiencia en materia de infraestructura vial que caracteriza a la ciudad, "las calles dan lástima, son terribles los pozos", no observa en esto un obstáculo para movilizarse. La posibilidad de contar con transporte privado también les permite visitar muchos de los atractivos naturales y paisajísticos que tiene Bariloche y, en general, la región andina, durante los fines de semana o los días que no tienen que trabajar.

Similar es el caso de Natalia de 42 años, residente también del San Francisco I, que junto a su marido de 45 y su hijo de 23 se movilizan permanentemente en transporte privado. El marido trabaja de camionero para el Municipio de Bariloche arreglando calles y, si bien sus recorridos se acotan al centro de Bariloche, se dedica plenamente a esa actividad: "si lo llaman a las 12 de la noche, tiene que ir a las 12 de la noche", resalta Natalia. Por otro lado, su hijo es chofer en el Hospital privado y, a diferencia de su padre, recorre todo el ejido de la ciudad. Ella, cuando ocasionalmente tiene trabajo, también se motoriza. Sin embargo, generalmente lo hace solo para llegar a un punto de destino, el casco céntrico; allí estaciona su auto y camina para hacer los diferentes trámites de cadetería que le encargan:

yo camino, mi trabajo lo hago caminando, siempre que no llueva; todo Bariloche caminando, porque no me da para el combustible, ni nada; lo que puedo lo camino, porque siento que no renegás con el estacionamiento, un montón de cosas; un montón de cosas, hasta la salud. Me encanta caminar también. Tengo problemas de salud, pero cuando ando bien, me gusta caminar, me gusta andar en patín. (Natalia, Hacia el San Francisco, 2018)

Sin dar muchos más detalles, descarta el uso del transporte público porque dice que le genera ataques de pánico y el olor le hace mal. No enfatiza demasiado en aspectos de infraestructura y equipamiento urbano como obstáculos a atravesar cotidianamente; la localización de su vivienda junto a conectores viales alternativos, les facilitan la salida (a diferencia de otros vecinos). Dejando a un lado los asuntos laborales, Natalia comenta que se moviliza mucho en auto para comprar y pasear, aunque también señala que es muy casera: su jornada laboral generalmente termina al mediodía, por lo que luego suele quedarse en su hogar, más allá de alguna compra o tarea doméstica. Los 
fines de semana o los días no laborales tienden a reducir sus traslados y hacer vida de entre casa. En repentina nostalgia, Natalia evoca: “Antes era más, por los días lindos. Nos gustaba; a mí me gustaba un montón ir a la costa del lago, hacer un camping, pero hace tiempo que no. Abandoné todo; dejé el alcohol, ja ja", agrega risueña. Indica que un impedimento es el económico, destacando que muchas de las excursiones que habitualmente se ofrecen en la ciudad solo son asequibles para los turistas.

A este respecto, Claudia es otra de las vecinas del barrio que acuerda con esta opinión: dice que hace poco fue la primera vez que se subió al teleférico del Cerro Otto, un cerro ubicado a cuatro kilómetros del centro. Ella es pensionada, tiene 58 años, y comparte el hogar con su hijo de 30. Sigue manteniendo su trabajo como empleada doméstica y, aunque ahora señala que no lo hace con tanta frecuencia, solía viajar mucho en colectivo, generalmente de lunes a viernes, a distintos puntos de la ciudad. Ahora viaja hasta cuatro veces por semana para realizar sus labores, utilizando dos líneas de colectivo cada vez que se dirige a los kilómetros, uno de sus destinos habituales:

De acá al centro me tengo que tomar 1 colectivo. Suponete que yo tengo que ir a los kilómetros, me tomo de acá al centro la línea 61 . Y del centro a los kilómetros me tomo el 50 o el 51. (Claudia, Hacia el San Francisco, 2018)

Claudia también cuenta que para llegar a sus trabajos tiene que salir con al menos 1 hora de tiempo: "yo tengo que salir muy temprano para llegar a horario...fácil, tardo 1 hora, y son 4 kilómetros". Resalta el largo tiempo de espera que tiene que hacer si se pierde el colectivo -y el horario incierto de algunas líneas- ya que en el mejor de los casos tarda 15 minutos, y a veces no pasa. Pero, además, después de bajarse del colectivo, tiene que caminar aproximadamente 7 cuadras en subida (cuando nieva o llueve mucho, la buscan sus empleadores). Si bien señala que es oneroso viajar en la ciudad, apunta que tiene descuento por ser empleada doméstica y pensionada. Descontando las veces que alguna amiga la traslada en auto, también utiliza el transporte público para sus compras cotidianas maximizando los viajes que realiza: "como vengo del centro, compro en el centro". Por otro lado, su hijo también es un usuario frecuente del transporte público. Trabaja en el aeropuerto y frecuentemente utiliza el único bus que tiene ese destino, que suele respetar el horario y pasar cada 20 minutos. Cuando llueve y/ o las condiciones climáticas no son las más favorables para caminar, usa un colectivo extra, pero no es lo usual y generalmente se dirige allí a pie. Refiriendo el clima y topografía de
Bariloche, Claudia dice resignada: "vivimos en una zona que tiene montañas. ¿Que sabemos? Un día tenemos calor, un día llueve, un día nieva, pero salir tenemos que salir". También comenta que antes caminaba más, pero dice que ya no lo hace por un problema físico en la pierna. Este es uno de los motivos por los que tampoco se moviliza demasiado los fines de semana o feriados, cuando no tiene obligaciones laborales y/o de aprovisionamiento doméstico. Otra es la situación de su hijo: "Mi hijo sí sale, allá por Playa Bonita; va al Lago. Él sí sale, pero yo no", agregando, de igual forma, que tampoco sale demasiado, y usa medios de traslado alternativos, como la bicicleta. Ella, por otro lado, cuando sale se dirige a destinos cercanos, casas de amigas y familiares, que le permitan caminar sin experimentar dolores físicos.

Estos achaques los sufre de manera más acentuada Ricardo, otro de los vecinos del San Francisco. Ricardo es jubilado, pero de tanto en tanto suele hace changas para una vecina. Tiene 65 años y convive con su hermano de 61 y su madre de 84 en un terreno compartido por toda la familia. Por dificultades propias de la edad y diversos problemas físicos, señalan que no suelen trasladarse demasiado por la ciudad, y ni siquiera por alrededores del barrio; recurren habitualmente a una sobrina para hacer sus diligencias: "va a comprarme el pan, un poco de fruta y ya está", señala la madre. El hermano de Ricardo es el que más se moviliza, aunque generalmente para comprar algún repuesto de automóvil, ya que tiene un taller mecánico en su domicilio. Es el único que usa un medio de transporte motorizado, una camioneta, tres o cuatro veces por semana ("si hago 10 kilómetros es mucho", señala), ya que el resto de los miembros del hogar apenas camina. Y en los casos en que deben aprovisionar el hogar, se trasladan en taxi hasta algún supermercado. Se levantan y se acuestan tarde, y la mayor parte del día permanecen en su casa, realizando tareas domésticas, en el caso de la madre de Ricardo, o trabajando en el taller contiguo, en el caso de su hermano. Los fines de semana, este último suele ir a la cancha en su camioneta o a alguna jineteada, pero en general son salidas puntuales. En conjunto, ninguno de ellos suele salir demasiado de su hogar; de hecho, afirman que no conocen mucho a sus vecinos (habitan hace más de 40 años el San Francisco). No se trasladan o viajan a ningún lugar porque "vos dejás la casa sola y entran las ratas", señala la señora; "nosotros no somos de salir", completa el hermano, y añade: "fui al catedral cuando era joven, a trabajar nomás".

Finalmente, como caso contrapuesto al de Claudia y, sobre todo, al de Ricardo, se encuentra Wanda, de 22 años. Ella vive con su cuñado y su hermana, ambos de 36 , y su 
sobrina, de 11. Wanda no solo experimenta habitualmente una mayor cantidad de traslados que el resto de los entrevistados, sino que a su vez son más diversos. En esto tiene que ver mucho el hecho de residir con la familia de su hermana, y las funciones domésticas que desempeña para ayudar en el hogar, particularmente el cuidado de su sobrina. Su hermana trabaja de docente en distintas escuelas y siempre se moviliza en auto, mientras que su cuñado trabaja en un galpón de un supermercado cercano a la vivienda, por lo que usualmente camina para llegar a destino (5 cuadras), y solo usa el auto los miércoles, cuando juega al fútbol. Wanda destaca que no todos sus días son iguales, dependiendo de si debe encargarse o no de llevar a su sobrina al colegio. Dice que se turna con su hermana cuando esta trabaja: los lunes y los martes cursa en la Universidad y el resto de los días hábiles cuida de su sobrina. En un caso como en otro, hace siempre sus trayectos en colectivo. En un día viernes típico como el que concertamos la entrevista, detalla:

Despierto a mi sobrina, después le hago de almorzar, la traigo a la escuela a eso de la 1 , después me pasa a buscar mi hermana, cerca de donde dejé a mi sobrina y nos vamos hasta la casa. Mi cuñado llega a las 2, caminando hasta la casa, y mi hermana trabaja de 4 a 5 ; entonces se van los dos juntos y a las 5 mi cuñado pasa a buscar a mi sobrina, que sale del colegio, y vuelven a casa. Yo, por lo general, los viernes voy a la casa de mi novio o a lo de mis amigos; no hago más nada. (Wanda, Hacia el San Francisco, 2018)

Los días en que se debe quedar con su sobrina, Wanda sigue yendo a la Universidad, aunque lo hace por la noche (los miércoles). Otros días, también, hace doble turno, cursando por la mañana y por la noche: regresa al mediodía a comer y luego parte nuevamente (señala que los estudiantes tienen hasta 4 pasajes gratuitos, y a partir del quinto tienen descuento). Cuando no cursa, también suele ir al centro para hacer algún trámite o comprar provisiones para el hogar, por lo que termina realizando semanalmente 4 traslados de colectivo diarios. Informa las dificultades que acarrea muchas veces el uso de este medio de transporte, apuntando que la línea 60 da muchas vueltas para llegar a destino, debiendo contar con 30 minutos extra para poder llegar a tiempo al colegio de su sobrina. Más allá de este caso, en general observa que los colectivos tienden a adelantarse o retrasarse 5 minutos, lo cual no solo termina alargando mucho más su espera, sino que llega tarde a sus destinos. Wanda señala que, si tiene tiempo, prefiere ir caminando, sobre todo en verano, y evitar trasladarse en el 60:
El 60 tiene un montón de problemas cuando nieva porque, por ejemplo, acá en mi casa, el colectivo no puede arrancar, para y le cuesta arrancar porque es medio en subida, y hay una parte en donde el cole se balancea bastante para poder pasar, y hasta da miedo. Lo que hacemos los pasajeros es pasarnos para el otro lado para balancearlo. (Wanda, Hacia el San Francisco, 2018)

Indica también algunas otras dificultades derivadas del estado ruinoso de las calles:

La calle Monteverde se rompe un montón, cuando llueve, más cuando nieva, se pocea un montón; no conozco algo tan poceado, y los problemas que esto trae aparejado para el desempeño vehicular del colectivo, como a veces tiene rotos los amortiguadores, te hace remarearte, te descompone a veces; es mucho lo que se rompe. (Wanda, Hacia el San Francisco, 2018)

Respecto a los fines de semana o días que no tiene obligaciones, refiere algunos recorridos típicos que hace con su novio que no la atan a su hogar o al universo barrial donde reside. Indica que depende del clima para salir, ya que deben caminar un buen tramo hasta llegar a la parada del colectivo: "cuando está lindo, por lo general vamos con mi novio al Campanario. Como él vive en el San Francisco 1, yo bajo caminando a su casa y nos tomamos el 20 o, más en verano, el 50". Generalmente, recorren el lago Gutiérrez durante la temporada estival, al cual llegan luego de una hora y media de viaje, entre la espera y la duración de los dos viajes colectivos que deben tomar para llegar allí. En invierno, las distancias se acortan y cambian los destinos: sale con su novio solo hasta el centro, a tomar algún helado, pasear por la costanera o visitar algunos amigos. En la dinámica de estos desplazamientos, Wanda contrapone su situación a la del resto de los miembros de su hogar, reconociendo la facilidad de traslado que ellos disponen al contar con un auto.

Casa de Piedra y "los kilómetros". Sobre el kilómetro 14 de la Avenida Bustillo y hacia el extremo sur del barrio Casa de Piedra, casi en sus confines (y a quince cuadras de la Avenida, para ser más exactos), viven Susana, de 62 años, y Manuel, de 68. Manuel trabaja como empleado a tiempo parcial en una Fundación y también de casero en varias viviendas de la zona de Llao Llao, por lo que habitualmente se dirige hasta allí en su camioneta para realizar, mayormente, tareas de jardinería. Además, dispone de un auto particular que lo usa en contadas ocasiones para travesías largas o determinados días de la semana que 
no debe trabajar. De acuerdo a Susana -la entrevistada-, sus desplazamientos cotidianos abarcan la extensa zona Oeste, desde el kilómetro 9 hasta el 21: "En Llao Llao tiene varias casas que cuida, y se mueve en su camioneta de un lugar a otro, porque tiene que cruzar la península (San Pedro), y él hace todo el circuito de la península". Por otro lado, en la Fundación donde trabaja es frecuente que realice tareas de cadetería, implicándole viajes regulares al centro; estas actividades, sin embargo, las comete usando el transporte público. Susana también cuenta con automóvil propio, aunque al momento de la entrevista lo había vendido y estaba esperando que la concesionaria le entregara uno nuevo. Transitoriamente utiliza su moto o el colectivo para realizar sus incursiones por la ciudad, que son variadas y, generalmente, orientadas a fines laborales (apunta que caminar no es una alternativa ni siquiera intrabarrial, dada la lejanía de los centros comerciales de aprovisionamiento y los perros que asolan a los peatones desprevenidos). Trabaja de modista y, si bien suele recibir a sus clientes y alumnos en su casa, también los visita:

cuando tenía movilidad daba cursos y me iba, cuando tenía el auto, con un Fiat, a ver mis alumnas, a trabajar; todo en el auto. Ahora que no tengo auto, me muevo en colectivo y, depende el día, en moto; cargo la mochila, con mis cosas y me voy en moto. (Susana, Casa de Piedra, 2018)

Susana refiere que a veces hace hasta 3 viajes en el día por su trabajo "por eso para mí el auto es muy necesario". Dice que solo 1 vez por semana hace un trayecto fijo, cuando también ella cuida una casa; en ese caso, en algunas ocasiones, usa el auto de sus patrones. Durante la semana suele viajar hasta 3 veces, y en cada una de ellas recorre distintos lugares: "para mí el vehículo es mi casa", señala. Por este motivo lamenta que circunstancialmente deba trasladarse en moto, ya que además de tardar 40 minutos en llegar al centro, su traslado en este medio depende de las buenas condiciones meteorológicas. La opción del colectivo tampoco la termina de convencer: "yo acá tengo que tomarme el 21; el 21 pasa cada media hora, porque encima ni siquiera pasa cada veinte o quince minutos: yo pierdo el de las y cuarto y perdí, yo ya llego tarde al trabajo". Y añade otras complicaciones del transporte público:

tengo que llegar con el 21 al centro y de ahí ya tengo que tomarme otro colectivo. Y ponele que yo me tengo que mover a ciertos lugares: yo tengo que tomarme un colectivo para ir a El Frutillar (un barrio de Bariloche ubicado al Sudoeste) y ya me queda a trasmano el que me lleva al San Francisco tercero o al cuarto; se me complica porque yo tengo que tomar el 6o y regresar al centro, y del centro tengo que retomar para ir al tercero...o irme a Dina Huapi (una localidad situada a 15 kilómetros de Bariloche). (Susana, Casa de Piedra, 2018)

Y, además, el clima:

Bueno, Bariloche, desde ya, es más que obvio que el clima es un problema. Si vos no tenes un medio de movilidad, el clima es un dolor de cabeza. Si tenés que esperar el colectivo te mojás hasta las orejas. Y en invierno, cuando hay mucha nieve, el 21 a veces ni anda. (Susana, Casa de Piedra, 2018)

Susana resalta esta diferencia al usar el auto y la disponibilidad que tiene para viajar libremente a cualquier lugar sin tener que depender de horarios, ni sufrir el frío o la lluvia:

no es que tiene que tener uno, tiene que tener la pareja vehículo, porque el marido se tiene que mover en una situación y la mujer en otra: no tenés otra opción, al menos en este barrio, porque los colectivos no te respetan. (Susana, Casa de Piedra, 2018)

En este sentido, resalta la funcionalidad del automóvil para otros usos, más allá de los laborales, cuando toma un curso en la universidad o hace gimnasia, por ejemplo. También en los momentos de recreación, durante los fines de semana junto a Manuel. Si los acompaña el clima, sobre todo en verano, recorren distintos lugares de la región andina: Villa Llanquín, El Bolsón, Villa La Angostura, Mascardi, Circuito chico, etc.

Otro caso de movilidades múltiples lo representa Federico y su familia. El hogar lo componen el entrevistado, de 44 años, su esposa de 45, y su hijo y su suegra, de 7 y 85 años, respectivamente. Federico resalta el vínculo estrecho que tiene con los automóviles que disponen "básicamente, tenemos dos autos, bah, tres, uno que es muy viejito y anda medio para atrás", ya sea para ir a trabajar, él y su esposa, como para llevar a su hijo al colegio, a diez kilómetros de donde viven. También agrega que su suegra prácticamente no se traslada a ningún lado, apenas camina, y cuando lo hace la ayudan y transportan ellos en sus distintos vehículos. Federico y su esposa trabajan en el centro Atómico, a cuatro kilómetros del barrio, y su hijo cursa en un colegio ubicado en el kilómetro cuatro, yendo hacia el centro. Generalmente ella es la que lo lleva; él se dirige directamente al trabajo. Salvo salidas ocasionales, como 
ir al médico o hacer trámites, permanecen en el Centro Atómico hasta la hora de salida, cuando uno de los dos regresa al colegio a buscarlo, aunque eso no significa que retornen directamente a sus hogares. Explican que tienen dos autos por comodidad, básicamente: "como nos dividimos en ir a buscarlo, resulta más fácil así. Pero realmente es una cuestión de comodidad, no hay una cuestión, que vos digas, de peso. Podríamos organizarnos para usar un solo auto, definitivamente". No consideran el uso de otros medios de transporte: "La realidad es que el colectivo pasa por la puerta de mi casa, pero no lo usamos". Indica que a lo largo de los 11 años que viven en el barrio, solo lo usaron dos o tres veces. También lo ha usado ocasionalmente, cuando ha tenido que dejar el auto en el taller, por ejemplo. Federico reitera que optan inexorablemente por el transporte privado: "claramente por una cuestión de comodidad; no hay otra opción. Agarramos el auto cuando queremos y salimos". Señala que siempre tuvieron al menos un auto, y que decidieron tener otro cuando nació su hijo. El automóvil le representa velocidad de traslado y comodidad:

Yo de acá (desde el Centro Atómico) no me voy a mi casa, me voy a buscar a mi hijo, o me voy al club, ¿entendés? Y después... hay claramente lugares donde no hay colectivos, cosas que realmente no las podés hacer. (Federico, Casa de Piedra, 2018)

También apunta que cuando vivía en Buenos Aires, sí solía utilizar el transporte público, aun teniendo auto particular, en parte porque su situación era otra, sin mayores obligaciones familiares, pero también porque el tráfico vehicular lo desalentaba a usar el automóvil. Algo similar le ocurre cuando debe ir al centro de Bariloche: dice que prefiere no ir y que insulta cada vez que tiene que hacerlo, sobre todo por los problemas para estacionar y el costo monetario que tiene hacerlo. También utilizan el auto para aprovisionarse de alimentos y enseres domésticos, ya que no suelen ir a los locales comerciales cercanos al barrio, a pesar de que comercialmente el área ha crecido mucho en los últimos años. Nunca les pareció problemático vivir lejos del centro: "la única complicación que yo identifico, que podría ser el invierno, que uno sabe que a medida que se va alejando del centro, si nieva, por ejemplo, se va poniendo más dura la cosa, definitivamente hay más nieve". Sin embargo, este factor climático no desalienta el uso del automóvil, al contrario:

Claramente el frío, me ayuda a que no agarre el colectivo, definitivamente. Asumo que acá en Bariloche tener auto es una ventaja comparativa con respecto a otras ciudades; definitivamente (...) la sensación que me da a mí acá es que una persona con el mismo poder adquisitivo en Buenos Aires el auto no lo compra; eso sí lo veo. Que puede ir en colectivo; se ahorra el gasto. Acá lo piensa. Eso sí lo ví: gente que ha hecho el esfuerzo para ganar tiempo. (Federico, Casa de Piedra, 2018)

Además, indica que, si nieva intensamente, tampoco ingresa el colectivo al barrio. Son casos extremos los días que no se movilizan por este motivo, ya que en última instancia usan cadenas (además, tienen un vehículo de doble tracción). Respecto a la infraestructura vial, dice que las calles internas a los barrios están "bastante hechas pelotas": es común la formación de pozos y "serruchos". Durante los fines de semana dosifican el uso de los autos y utilizan más la bicicleta para sus paseos recreativos: "definitivamente, estamos más en casa". En general, amén de alternar en el invierno con el esquí, tienden a salir más en verano: la "dinámica del verano" es recorrer las playas solo durante las primeras tres semanas, de mayor entusiasmo inicial.

Otro de los vecinos del barrio es José Ignacio, de 60 años. Indica que la elección del lote y del barrio donde reside tuvo que ver con la cercanía al lugar de trabajo, el Centro Atómico: "Arranco yendo al trabajo al cual vuelvo al mediodía siempre; volver a almorzar a tu casa es una cuestión de calidad de vida, pero también por una cuestión de seguridad". Pudiendo hacer horario de corrido, refiere que prefiere esto porque la gente que tiene "horarios muy marcados y fijos, termina siendo robada". Si durante la tarde le quedaron cosas por hacer en su casa, se traslada hasta 3 veces al trabajo, volviendo durante la noche al Centro Atómico. Si el clima es bueno, ese trayecto lo hace en bicicleta o en moto, pero si es malo se moviliza en auto. José Ignacio señala que se reparte el uso de los medios de locomoción que dispone, independientemente de si es verano o invierno "porque es un trayecto muy corto; no llegas a resfriarte, ni es peligroso". A veces, cuando tiene tiempo, también camina hasta su trabajo. Sus viajes se desenvuelven en un radio cercano, ya que además del trabajo, cuando necesita proveerse de comida o artículos para el hogar, suele recurrir a comercios del barrio. Afirma que solo compra en el centro lo que no consigue en este, cuando visita 1 o 2 veces por semana a su pareja, porque generalmente prefiere evitar el viaje. Cuando debe trasladarse al centro, opta por el colectivo o el auto en función de la actividad y la carga que le impliquen los viajes. Dice que por su profesión (especialista en economía energética) "está muy deformado por el tema energético. Me da no sé qué mover un vehículo de dos toneladas para ir a hacer un trámite al centro. Entonces 
me parece más razonable, si todos lo pudiéramos hacer, tomar el colectivo". Sin embargo, apunta que "el transporte público no es muy bueno. No es puntual, tampoco es tan frecuente y en la noche está limitado". Afirma que también le pesa la distancia de 13 kilómetros y el tiempo que le lleva llegar hasta allí. Cuando no está obligado por el compromiso laboral, generalmente los fines de semana, José Ignacio trata de moverse en bicicleta recorriendo lugares cercanos:

Si voy al lago, voy al lago Moreno, que está al alcance de bici, o a Bahía Serena; o sea, trato de no hacer grandes movidas. Tengo como una fobia a meterme en el auto, y en la ruta y en el quilombo de autos. (José Ignacio, Casa de Piedra, 2018)

El clima lo sufre con relación a la lluvia y la nieve, particularmente, pero no el frío en sí mismo. A este respecto, agrega que el barrio "es interesante; es bastante plano y te lleva a muchos lados sin meterte en la ruta" (aunque también señala, como otros entrevistados, el problema de los perros sueltos y el deficiente estado de las calles).

Nancy es otra de las vecinas que está empleada en el Centro Atómico: tiene 50 años y vive con su hija de 10 . A contramano de los anteriores entrevistados, ella se traslada asiduamente en colectivo. Siempre lo utiliza para ir a su trabajo, aunque a veces se desvía hasta el kilómetro cuatro para llevar a su hija al colegio (otras veces la lleva el padre). En este último caso, suele llamar a un remise (se les llama así a los autos que se piden por teléfono para trasladarse; es un servicio similar al de radio-taxi), sobre todo en invierno cuando todavía está oscuro, puesto que la línea 21 , la más cercana a su domicilio, no las deja cerca, y deben caminar hasta la Avenida Bustillo (5 cuadras) para tomarse el colectivo 51, que sí las lleva directo al colegio. Una vez que deja a su hija, cuenta con más alternativas para dirigirse a su trabajo: toma el colectivo que tiene el Centro Atómico para su personal o bien la lleva alguno de sus compañeros de trabajo: "Para volver del colegio me llevan, porque hay muchos que tienen hijos en el mismo colegio". Si debe ir al centro, directamente retorna en transporte público: "no tengo un día estándar, pero básicamente para ir al centro me tomo el 21; lo uso mucho porque voy bastante al centro, así que, ya sea para ir o para volver, termino tomando el 21 ". Destaca que en el barrio "el 99\% tiene auto", pero a ella no le resulta tan incómodo el uso del colectivo porque lo compara con el tiempo que le insumía el viaje laboral en Buenos Aires (si bien le gustaría que el 21 tuviera una mayor frecuencia y las líneas de colectivo, en general, mayor conexión entre sí):
Hay veces que te tenés que tomar sí o sí dos colectivos para hacer un trayecto relativamente corto porque no hay conectividad, y como tenés que pagar dos veces el boleto terminas pagando más o igual que el que se toma el (colectivo de la línea) 20 en el centro y se va hasta el Llao Llao. (Nancy, Casa de Piedra, 2018)

A lo sumo, señala que, las dificultades las observa en otra franja etaria:

La movilidad para ancianos es complicada, porque más allá de que te pueda llevar un remise al centro para que la atienda un médico, es complicado porque en el centro no tenés estacionamiento, o tenés que estacionar en subida y tenés que bajar en el medio de la calle...para la gente grande, que ya no puede moverse tan bien, es una ciudad para nada amigable. (Nancy, Casa de Piedra, 2018)

Los problemas que detecta en la línea de colectivo que más utiliza tienen que ver con las roturas producidas por los pozos de las calles y cuando nieva mucho, ya que el barrio queda aislado y tiene que ir hasta la avenida Bustillo y rogar que pase alguno. No hay motivos económicos para que Nancy no tenga auto, sino una experiencia desagradable que le ocurrió hace unos años cuando todavía manejaba: un incidente con un colectivo que, junto a las dificultades que le implica estacionar, la hicieron sentir insegura. Más allá del colectivo, dice que camina mucho: no hasta el trabajo (puesto que le parece una distancia excesiva), pero sí en su tiempo libre. Los fines de semana frecuenta también el centro como lugar de paseo, de consumo (solo ocasionalmente compra en comercios cercanos) y esparcimiento, añadiendo que no tiene mucho contacto con la naturaleza: "tenemos a Bahía Serena que está cerca de casa, y la nena va con alguna amiguita, pero mucha cosa turística...no". Las raras ocasiones se dan cita cuando hay visitas: "Hace poco vinieron unos amigos de Buenos Aires y fuimos a hacer lacustre, a Puerto Blest, pero no es algo que me la pase haciendo, digamos".

Otros vecinos habitúes del transporte público son Darío, de 78 años, y su mujer, de 72, ambos con más de veinte años de residencia en el barrio. Sin embargo, sus razones difieren de las de Nancy: ellos disponen de transporte privado, pero prefieren no utilizarlo cuando deben realizar trámites. En palabras de Darío:

El auto casi no lo usamos porque es muy incómodo para estacionar en el centro. Por lo general, nosotros siempre nos vamos en colectivo. Cuando tenemos que hacer compras, por ejemplo, en el mayorista, vamos 
en el auto, pero si hay que pagar una cuenta vamos en colectivo; es más ágil. (Darío, Casa de Piedra, 2018)

Señala como problema la gran cantidad de vehículos que abundan en la ciudad: "Ha crecido mucho la cantidad de vehículos para lo que es Bariloche; ahora cualquiera tiene auto (...) ahora todos tienen auto en la casa". Afirma que lo nota mucho más en los horarios pico en la Avenida Bustillo, cuando la gente va a trabajar y lleva a sus hijos al colegio: "hay que ir a paso de hombre, en el kilómetro cuatro ya se empieza a ir despacito, despacito...; es tedioso eso. Si hay turismo o escuela es peor". Otro factor que también tiene en cuenta para elegir el medio de transporte público es el descuento que obtiene por ser jubilado. Al centro suelen trasladarse hasta dos veces por semana y casi para lo estrictamente necesario, sin que quepa en sus consideraciones algún paseo complementario. Con relación al tiempo que deben esperar el colectivo, que otros entrevistados consideran excesivo, Darío dice que ya están acostumbrados y agrega que sabe los horarios en que pasa para poder organizarse y tomarlo a tiempo, aunque añade que las esperas deberían ser menos espaciosas, en vez de media hora, cada veinte minutos. El clima tampoco afecta gravemente la circulación del colectivo, ya que cuando hay nieve, uno o dos días al año, se desvía por otra calle y no lo afecta (y si hay demasiada nieve, pasa la máquina). Indica que cuando era joven usaba más el auto y que, si bien hasta el año pasado hacía changas como topógrafo, hace años que está jubilado y sin mayores compromisos laborales. Su mujer es ama de casa y juntos suelen hacer distintas tareas generales de jardinería y cuidado del hogar; Darío comenta que no son de salir mucho y se quedan en casa: "tomamos mate, tengo el horno, hacemos asado, comemos aquí; no somos de salir mucho". Para compras menores, dentro del barrio, sí utilizan el automóvil, puesto que, aunque los comercios abarcan un área más accesible, la caminata no es una alternativa: "no, porque nos queda lejos y ya tenemos unos años encima; para venir con bolsos, no". Para actividades de esparcimiento, prefiere lugares cercanos al barrio. No suelen visitar sitios turísticos y de reconocido atractivo natural "porque ya hemos ido antes, cuando éramos más jóvenes" y porque también se reiteran los problemas de tráfico vehicular: "si vas a un lago de aquí (cercano a Casa de piedra), también tenés un problema para estacionar porque tenés que ir en auto".

\section{Resultados}

Entre los muchos condicionantes socioeconómicos y del entorno que hacen al acceso (Kaufmann et al., 2004), se verifica y reafirma, a partir de los relatos, la importancia crucial que adquiere la tenencia de transporte privado en la ciudad. El registro empírico verifica la necesidad ineluctable de disponer de automóviles: sea porque el transporte público generalmente no supone una alternativa eficiente y práctica para recorrer las largas distancias que presenta la ciudad - por su baja frecuencia y poca conectividad entre recorridos, fundamentalmente, pero también por el estado deficiente de su flota-, sea porque la geografía física dificulta los traslados aún hacia destinos cercanos. El auto no solo salva las grandes distancias, sino también los esfuerzos físicos que hay que hacer para subir calles estrechas y empinadas, con hielo, escarcha y bajo un entorno ambiental de muy bajas temperaturas durante la mayor parte del año (el uso del automóvil representa una complicación solo ante destinos puntuales, como ir al centro y lidiar con los problemas de estacionamiento). Así, las largas esperas en colectivo se hacen más largas y extenuantes, las caminatas más cansadoras y la posibilidad automotriz, aún bajo transportes precarios, un capital diferencial. Más allá del estado de la infraestructura vial - variable en cada barrio, pero, en general, igualmente deficiente-, el automóvil y las posibilidades económicas de hacer uso de él (gastos de combustible y mantenimiento, en general) terminan terciando, en una primera aproximación, en las desiguales capacidades de movilidad de uno y otro barrio. Esto particularmente se constata en los barrios más cercanos al casco céntrico, los San Franciscos, donde la mayor conectividad ofrecida es relativa, ya que los caminos accidentados y en subida mantienen su dificultad para los peatones. En estos barrios, donde es más variada la capacidad económica de los hogares para poder disponer de un automóvil, se estructura un primer condicionante a las movilidades potenciales de sus habitantes: los entrevistados que poseen auto destacan sus beneficios prácticos, así como las dificultades que encontrarían para moverse si dejaran de tenerlo. En tanto, los que no tienen automóvil, y hacen uso de transportes alternativos —el motorizado público o la caminata - a costa de mayores esperas y/o esfuerzos físicos y monetarios, denotan un mayor desaliento y reconocimiento de los problemas de traslado (detallando situaciones puntuales de funcionamiento de determinadas líneas de colectivo, por ejemplo). En cambio, la situación económica más favorable de los vecinos de Casa de Piedra, que en general refieren la tenencia de al menos 1 auto (los entrevistados que no lo tenían o no hacían uso de él aducían razones no económicas), los predispone a la realización de más y diversos trayectos por la ciudad, diluyendo la distancia física como principal barrera. De hecho, no son infrecuentes los casos de dos o más vehículos, incluyendo motos, de uso privado (en los San Francisco, la disponibilidad de más de un auto se vinculaba casi exclusivamente a una relación laboral). Si bien conocen los horarios y frecuencias del transporte 
público - y hasta en algunos casos les gustaría usarlo con más frecuencia-, terminan decantándose por el automóvil: el colectivo es utilizado esporádicamente ante algún percance mecánico o actividades específicas que implican viajar hasta el casco céntrico. Esto indica también la mayor dependencia, mediada por la distancia, hacia el automóvil por parte de los vecinos de Casa de Piedra, aun cuando en sus adyacencias se encuentre en vías de consolidación un polo comercial y de servicios que, en buena medida, podría evitar y/o reducir los traslados al centro.

Pero el acceso constituye solo una de las dimensiones del capital de movilidad, o motilidad. Si bien en las entrevistas queda en evidencia la incidencia de las condiciones socioeconómicas en las capacidades de movilidad de los entrevistados, las habilidades y/o competencias que detentan también intervienen para facilitar los trayectos, sobre todo en aquellos casos en que el transporte privado no es una opción. Aquí comienza a pesar la condición etaria: aunque no siempre dispongan del tiempo necesario, los más jóvenes pueden muchas veces sobrellevar las distancias, las bajas temperaturas y/o el funcionamiento irregular del transporte público; las personas de mayor edad, por el contrario, tienden a optar por quedarse en sus casas cuando no tienen obligaciones laborales. A su vez, también operan otros saberes propios del entorno, como la organización de los viajes y el reconocimiento de los tiempos que deben esperar el colectivo o las horas menos recomendadas para salir, o el hecho de saber conducir (Flamm \& Kaufmann, 2006). Estas habilidades son más visibles en los barrios San Francisco, donde obligadamente o por elección los vecinos deben recurrir al colectivo o la caminata y lidiar cotidianamente con las inclemencias climáticas - ya mencionadas - y/o los tiempos de viaje del transporte público. En el caso de Casa de Piedra, estas habilidades suelen circunscribirse al entorno barrial, al reconocimiento de los lugares a sortear (por existencia de perros o estado de las calles), y las condiciones de funcionamiento de los medios de transporte público. Sin embargo, no constituyen, en general, saberes que estructuren significativamente sus movilidades. Al primar el uso de transporte privado, las competencias necesarias se reducen al hecho de poder contar con una licencia de conducir - esto es, saber manejar - y la experticia de acondicionar sus vehículos para los imponderables que puede presentar el clima y las calles del barrio como, por ejemplo, grandes nevadas o lluvias intermitentes.

Finalmente, cabe agregar unas palabras respecto a la apropiación de los entrevistados de sus experiencias de movilidad, de los trayectos que realizan y los que potencialmente podrían hacer en función de sus condiciones de acceso y sus habilidades o competencias (Kaufmann et al., 2004). En general, en los barrios San Francisco se observa un comportamiento más utilitario de los traslados, sobre todo si las opciones de transporte se reducen al transporte público (y a la obligada realización de dos o más viajes) o a la caminata. La economía de los traslados se evidencia en la maximización de los trayectos obligatorios vinculados a lo laboral o educativo, aprovechándolos para la recreación o la realización de alguna compra. Esta apropiación de otros espacios urbanos de la ciudad varía también en función de las posibilidades físicas de cada vecino - en función de su edad, sobre todo_-, para hacer frente a las condiciones más adversas que puedan sucederle (como se mencionó, el traslado a pie está reservado para los más jóvenes o para recorrer distancias todavía más cercanas, como puede ser la visita a algún vecino). Esto se torna notorio en las descripciones de los trayectos de viaje cotidianos, que no solo son más acotadas sino también mucho más precisas que las que suelen relatar los que se movilizan en automóvil ${ }^{1}$. La mayor estructuración de los trayectos en los San Francisco, - aun para los que cuentan con automóvil, pues también la economización de su uso, actual o potencial, se presenta en sus relatos - sujeta a sus habitantes a movilidades más lineales (Chaves, Segura, Speroni \& Cingolani, 2017) y de apego a su entorno barrial. En Casa de piedra, en cambio, pesa más el disfrute, la comodidad y el confort que brinda la posibilidad de moverse de distintas maneras, utilizando más y diversos medios de transporte privados. El recorrido más expeditivo de estos, sean autos o motos, y su contraste frente a los problemas de funcionamiento del transporte público, permite ampliar y diversificar la elección de los destinos, entre los que se encuentran muchos de los atractivos turísticos de la ciudad. Así, la libertad que ofrecen transportes privados como el automóvil ensanchan el abanico de los viajes posibles sin que necesariamente impliquen su concreción (Gutiérrez, 2012). Por otro lado, el contacto con el barrio y sus alrededores durante los fines de semana aparece más como una opción vinculada al uso recreacional de medios de transporte alternativos al auto y, por transmisión, ajenos a la cotidianeidad que representa su uso durante los días hábiles, más que una restricción de los viajes posibles como sí se identifica en los San Francisco.

\section{Conclusiones}

En la introducción del artículo se señalaban algunas características físicas y ambientales de San Carlos de

${ }^{1}$ Esto se acentúa los fines de semana o los días de mayor tiempo de ocio, puesto que la reducción de las frecuencias de las líneas de colectivos alarga la espera, y la mayor cantidad de traslados en algunos tramos (2 o más) y la duración de los viajes, en general, para alcanzar largas distancias desalienta los viajes con fines recreativos y/o no vinculados a un fin laboral. 
Bariloche que habían intervenido en la cristalización de sus desigualdades espaciales. A partir de estas desigualdades reconocidas en el territorio y localizadas en áreas precisas de la ciudad, se propuso indagar en las asimetrías que podrían derivarse de las capacidades de movilidad de dos barrios distantes, física, social y económicamente: El barrio Casa de Piedra y los San Francisco.

Se pudo constatar que los habitantes de uno y otro barrio presentan distintas capacidades de movilidad que, al momento de diagramar sus trayectos de viaje y elegir los medios para hacerlos efectivos, se materializan, fundamentalmente, a partir de la posesión (o no) de medios de transporte privados. La tenencia de uno o más automóviles en un clima generalmente gélido y de caminos escabrosos precipita los mayores y diversos traslados que, en el caso de los dos barrios de estudio, decide significativamente la experiencia urbana en la ciudad. En este orden, el transporte público no comporta una opción viable, dada su baja frecuencia y el deficiente estado de algunas de sus unidades, que suelen sufrir desperfectos debido, en buena medida, a las condiciones ruinosas de gran parte de las calles (incluso las que cuentan con pavimento).

La motilidad o capital de movilidad, de acumulación diferencial en estos dos barrios, se evidencia sobremanera en los tiempos que los vecinos disponen de ocio y, particularmente, en las distintas relaciones de apropiación que mantienen con el espacio urbano barilochense. En aquellas circunstancias en que no media el compromiso laboral es donde es más clara la incidencia del medio físico, la existencia de infraestructura vial acorde y, sobre todo, la disponibilidad de automóvil, en las decisiones de desplazamiento (o inmovilidad). El entorno ambiental desalienta, acaso más acentuadamente que en otras ciuda $\neg$ des, la concreción potencial de estos viajes si no se cuenta con medios de transporte privado. Otras alternativas de locomoción, transporte público o a pie, son generalmente encaradas por algunos vecinos, cuya condición etaria y estado físico les permite enfrentar mejor los desplazamientos en dichos medios, alcanzando destinos no necesariamente sujetos al espectro barrial. Sin embargo, estos casos particulares, que logran atenuar desiguales condiciones de acceso mediante habili $\neg$ dades temporarias (como las que derivan de su juventud) no hacen más que evidenciar la problemática de la movilidad (y especialmente la falta de oferta de transporte público que logre paliarla). Estas limitaciones a los desplazamientos pasibles de ser realizados, que hacen a las desiguales capacidades de movilidad de los barrios analizados bien podrían extenderse - con matices - a otros casos. Es plausible que nuevos registros empíricos en otros barrios terminen de corroborar no solo como las asimetrías se manifiestan en el acceso a determinados lugares de estudio y oportunidades laborales, sino también como toman forma en la experimentación de los reconocidos atractivos naturales de la ciudad.

\section{Referencias}

Abaleron, C. A. (1992). Tendencias de crecimiento poblacional y espacial en San Carlos de Bariloche con énfasis en el sector marginal: Informe final. San Carlos de Bariloche: Biblioteca Fundación Bariloche.

Blanco, J., Bosoer, L., \& Apaolaza, R. (2014). Gentrificación,movilidadytransporte:aproximaciones conceptuales y ejes de indagación. Revista de geografia Norte Grande, 58, 41-53. https://dx.doi. org/10.4067/S0718-34022014000200003

Chaves, M.; Segura, R.; Speroni, M. y Cingolani, J. (2017). Interdependencias múltiples y asimetrías entre géneros en experiencias de movilidad cotidiana en el corredor sur de la Región Metropolitana de Buenos Aires (Argentina). Revista Transporte $y$ territorio, 16, 41-67.

Cresswell, T. (2011). Constellations of mobilities. Recuperado de http://www.dcuci.univr.it/documenti/ Avviso/all/all181066.pdf

Errázuriz, T. (octubre, 2014). Pasajeros mecanizados y vida metropolitana: la nueva experiencia del viaje colectivo en Santiago. Ponencia presentada en XIV Jornadas de Interescuelas de Historia, Mendoza, Argentina.

Flamm, M. \& Kaufmann, V. (2006). Operationalising the conceptofmotility:Aqualitativestudy. Mobilities, 1(2), 67-189. https://doi.org/10.1080/17450100600726563

Galimberti, C. (2018). Dispersión urbana en relación con los sistemas de movilidad: caso región metropolitana de Rosario. Revista de Urbanismo, 38, 1-19. https:// doi.org/10.5354/0717-5051.2018.48222

Geertz, C. (1987). La interpretación de las culturas. Barcelona: Gedisa. 
Guevara, T. y Medina, V. D. (2017). Las transformaciones urbanas y perfiles socioeconómicos en barrios de San Carlos de Bariloche: análisis a partir de una encuesta. Unidad Sociológica, 9(3), 6-19.

Gutierrez, A. (2012). ¿Qué es la movilidad? Elementos para (re) construir las definiciones básicas del campo del transporte. Bitácora urbano territorial, 2, 61-74.

IRV LOGIT (2014). Estudio de Movilidad Urbana Sustentable. San Carlos de Bariloche: Banco Interamericano de Desarrollo.

Jirón, P. (2007). Implicancias de género en las experiencias de movilidad cotidiana urbana en Santiago de Chile. Revista venezolana de estudios de la mujer, 12(29), 173-197.

Jirón, P.; Lange, C., y Bertrand, M. (2010). Exclusión y desigualdad especial. Retrato desde la movilidad cotidiana. Revista Invi, 68(25), 15-57. http://doi. org/10.4067/S0718-83582010000100002

Kaufmann, V.; Bergman, \& M. Joye, D. (2004). Motility: Mobility as capital. International Journal of Urban and Regional Research, 24(4), 745-756. https://doi. org/10.1111/j.0309-1317.2004.00549.x

Kropff, L. (octubre, 2002). Juntas vecinales en Bariloche: una historia en disputa. Ponencia presentada en el Primer encuentro patagónico de Ciencias Sociales, Esquel, Chubut, Argentina.

Martinez, C. y Santibañez, N. (2015). Movilidad femenina en Santiago de Chile: reproducción de inequidades en la metrópolis, el barrio y el espacio público. Revista Brasileira de Gestão Urbana, 7(1), 48-61. https://doi.org/10.1590/2175-3369.007.001. ao03

Matossian, B. (septiembre, 2011). Dimensiones objetivas y subjetivas de la segregación urbana: el caso de San Carlos de Bariloche. Ponencia presentada en las XI Jornadas Argentinas de Estudios de Población, Neuquén, Argentina. Recuperado de http://www. redaepa.org.ar/jornadas/xijornadas/sesiones/ S14/s\%2014matossian.pdf
Medina, V. D. (2017). El crecimiento urbano de una ciudad turística y las políticas de ordenamiento territorial. El caso de San Carlos de Bariloche y el Plan Director de 1979. Revista de Urbanismo, 36, 1732. http://dx.doi.org/10.5354/0717-5051.2017.44368

Méndez, L. (2010). Estado, frontera y turismo: Historia de San Carlos de Bariloche. Buenos Aires: Prometeo Libros.

Merriman, P. (2014) Rethinking mobile methods. Mobilities, 9(2), 167-187. https://doi.org/10.1080/17 450101.2013.784540

Mohana, C. (2004). Estudio de Transporte Urbano de Pasajeros, Taxis, Remisses y Transporte Escolar de San Carlos de Bariloche. San Carlos de Bariloche: Municipalidad de San Carlos de Bariloche.

Muñoz, D. (2013). Experiencias de viaje en Transantiago/ La construcción de un imaginario urbano hostil. Bifurcaciones, 15, 1-14.

Ohnmacht, T.; Maksim, H.-N., \&Bergman, M. (2009). Mobilities and Inequality. London: Routledge.

Municipalidad de San Carlos de Bariloche. (2010). Plan de ordenamiento territorial. San Carlos de Bariloche: Municipalidad de San Carlos de Bariloche.

Pérez, V. (2014). Viajar en la ciudad. Movilidad, padecimiento y disconformidad entre los pasajeros de transporte ferroviario del área metropolitana de Buenos Aires. Argumentos, 14(16), 315-343.

Pérez Negrete, M. (2015). Sobre movilidades e inmovilidades: un acercamiento etnográfico a la construcción de la desigualdad en la ciudad de México. Espacialidades, 5(2), 148-175.

Schivelbusch, W. (1986). The Railway Journey: The Industrialization of Time and Space in the Nineteenth Century. Berkeley: University of California Press.

Sheller, M., \& Urry, J. (2000). The city and the car. International Journal of Urban and Regional Research, 24(4), 737-757. https://doi. org/10.1111/1468-2427.00276 
Sheller, M., \& Urry, J. (2006). The new mobilities paradigm. Environment and Planning, 38, 207-226. https://doi.org/10.1068/a37268

Suárez, O. (1977). Plan de ordenamiento urbano San Carlos de Bariloche. Buenos Aires: Consejo Federal de Inversiones.

Wolfe, J. (2010). Autos and progress: The Brazilian search for modernity. Oxford: Oxford University Press.

Zunino Singh, D. (2014). Meaningful Mobilities: The Experience of Underground Travel in the Buenos Aires Subte (1913-1944). Journal of Transport History, 5(1), 97-113. https://doi.org/10.7227/ TJTH.35.1.7

\section{Agradecimentos}

Agradezco especialmente al Consejo Nacional de Investigaciones Científicas y Técnicas (CONICET) por la beca posdoctoral que permitió materializar esta investigación. También al Centro Interdisciplinario de Estudios Territoriales Económicos y Sociales (CIETES) de la Universidad Nacional de Rio Negro que me proporcionó un lugar de trabajo. 